\title{
Reformed Environmental Impact Assessment in China: An Evaluation of Its Effectiveness
}

\author{
Yang Yang \\ Graduate School of Global Environmental Studies, Kyoto University, Kyoto, Japan \\ Email: yang.yang.64n@st.kyoto-u.ac.jp
}

How to cite this paper: Yang, Y. (2020) Reformed Environmental Impact Assessment in China: An Evaluation of Its Effectiveness. Journal of Environmental Protection, 11, 889-908. https://doi.org/10.4236/jep.2020.1110056

Received: September 16, 2020

Accepted: October 20, 2020

Published: October 23, 2020

Copyright $\odot 2020$ by author(s) and Scientific Research Publishing Inc. This work is licensed under the Creative Commons Attribution International License (CC BY 4.0).

http://creativecommons.org/licenses/by/4.0/

(c) (i) Open Access

\begin{abstract}
Since 2015, a "reform storm" of Environmental Impact Assessment (EIA) opened up in China. This study tries to answer the question of whether these reforms improve the effectiveness of EIA. First, we elaborate on the reforms along with three well-acknowledged components, including EIA legislation, administration, and process. Then, evaluate the reformed EIA system against revised Ahmad and Wood's criteria. The results demonstrate that the revised laws and regulations are more stringent than the old versions. The EIA process is simplified, and its coordination with the pollutant discharge permit system is promoted. The interim and post-event supervision is currently more robust and the penalties are more severe than before. However, the hierarchical position of the Environmental Protection Law is not high enough and the coordination of different government departments is still challenging. In summary, despite the problems occurring at the initial phase of reforms, the effectiveness of the EIA system has largely been improved.
\end{abstract}

\section{Keywords}

Environmental Impact Assessment, Reform, Evaluation, Effectiveness

\section{Introduction}

As one of the essential preventive environmental protection measures, Environmental Impact Assessment (EIA) has been developed in China for more than four decades. Although it has evolved into a fairly comprehensive and technically adequate system, there still exist many problems as to its performance [1] [2]. Significantly, six severe problems in China's EIA system were pointed out by the third inspection team organized by the national government in 2015, which include: 1) some developers proceed construction projects before getting EIA approval, 2) some leading cadres and their relatives illegally intervene in the EIA 
approval process or set up agencies to undertake EIA, 3) a large number of EIA agencies are government-affiliated, which practically play a dual role of both evaluators and reviewers, 4) some EIA agencies get licenses through bribes, 5) some government departments give EIA approval leniently or neglect the post-event supervision, and 6) some local environmental protection departments are prone to corruption during the EIA approval process [3]. Subsequently, an EIA "reform storm" opened up and a series of reforms took place.

\subsection{The Reforms on EIA}

Under the guidance of "Implementation Plan for the Reform of EIA in $13^{\text {th }}$ Five-year Plan (2015-2020)", reforms have been carried out aiming to streamline administration, delegate more powers, improve regulation and provide better service [4]. In March 2015, the Ministry of Environmental Protection (MEP) issued the "Plan for Decoupling of EIA Agencies from Environmental Protection Department" and started to abolish the "Government-affiliated Intermediary Agency". All those EIA agencies are required to change to companies or withdraw from the EIA service market by the end of 2016. From January 2017, the EIA approval for the Environmental Impact Registration Form (EIRF), which is required to be compiled by those projects causing little environmental impacts, has been cancelled and only needs to complete the online registration. With this change, it is expected to reduce the cost of EIA approval and increase its efficiency. In December 2018, the qualification management for EIA agencies was canceled (REPMCP, 2017). The agencies were not classified into the $1^{\text {st }}, 2^{\text {nd }}$ or $3^{\text {rd }}$ grade, and a certain number of EIA engineers in each agency were not indispensable anymore, which was expected to reduce the chaos of certificate borrowing and attachment. Afterward, the Ministry of Ecology and Environment (MEE) was established. The MEE, replacing the former MEP, takes the overall responsibility for the environmental management and ecological protection and opens a new era of "super-ministry" [5]. The list of reforms is summarized in Table 1 .

Table 1. The list of reforms since 2015 and comparison of the EIA system before and after reforms.

\begin{tabular}{|c|c|c|c|}
\hline \multirow[t]{2}{*}{ EIA reforms } & \multicolumn{2}{|l|}{ EIA system } & \multirow{2}{*}{$\begin{array}{l}\text { Start of the } \\
\text {-reform }\end{array}$} \\
\hline & Before reform & After reform & \\
\hline Establishment of MEE & $\begin{array}{l}\text { The environmental protection duties } \\
\text { dispersed in different departments. }\end{array}$ & $\begin{array}{l}\text { MEE oversees and coordinates the environmental } \\
\text { protection work nationwide. } \\
\text { The EIA and Emission Management Department in } \\
\text { MEE is responsible for the implementation of EIA. }\end{array}$ & 2018.4 .16 \\
\hline $\begin{array}{l}\text { Vertical management } \\
\text { reform of environmental } \\
\text { monitoring and } \\
\text { enforcement } \\
\text { departments below the } \\
\text { provincial level }\end{array}$ & $\begin{array}{l}\text { The environmental protection } \\
1 \text { authorities are under the management } \\
\text { of local municipal governments. }\end{array}$ & $\begin{array}{l}\text { The management of environmental protection } \\
\text { authorities belongs to higher-level environmental } \\
\text { protection authorities. } \\
\text { - The supervision responsibility belongs to the provincial } \\
\text { level. } \\
\text { The responsibility of law enforcement decentralized to } \\
\text { the city and county level. }\end{array}$ & $\begin{array}{l}2016 \\
\text { Guidance for pilot } \\
\text { work of vertical } \\
\text { lmanagement } \\
\text { reform }\end{array}$ \\
\hline
\end{tabular}




\section{Continued}

\begin{tabular}{|c|c|c|c|}
\hline $\begin{array}{l}\text { Decoupling of EIA } \\
\text { agencies from the } \\
\text { Environmental } \\
\text { Protection Department }\end{array}$ & $\begin{array}{l}\text { Exists "Government-affiliated } \\
\text { Intermediary Agency" }\end{array}$ & $\begin{array}{l}\text { - All the "Government-affiliated Intermediary Agencies" } \\
\text { change to enterprises or withdraw from the EIA service } \\
\text { market. }\end{array}$ & $\begin{array}{l}2015.3 .25 \\
\text { Plan for } \\
\text { decoupling of EIA } \\
\text { agencies }\end{array}$ \\
\hline $\begin{array}{l}\text { Canceling the } \\
\text { qualification } \\
\text { management of EIA } \\
\text { agencies }\end{array}$ & $\begin{array}{l}\text { The EIA agencies are classified into } \\
\text { three grades, which require a different } \\
\text { number of engineers. }\end{array}$ & $\begin{array}{l}\text { Grade management is canceled. The government does } \\
\text { not issue a certificate to EIA agencies. } \\
\text { Companies can prepare EISs. }\end{array}$ & $\begin{array}{l}2016.7 .2 \\
\text { EIA law (2018) }\end{array}$ \\
\hline $\begin{array}{l}\text { Canceling the } \\
\text { preconditions of EIA } \\
\text { review }\end{array}$ & $\begin{array}{l}\text { For the project related to soil and water } \\
\text { conservation, the conservation methods } \\
\text { should be reviewed firstly by the } \\
\text { industrial authorities. }\end{array}$ & - The preconditions have been canceled. & $\begin{array}{l}2017.10 .1 \\
\text { REPMCP }\end{array}$ \\
\hline $\begin{array}{l}\text { Simplifying the EIA } \\
\text { approval process }\end{array}$ & - EIRF required to be reviewed by EPBs. & $\begin{array}{l}\text { EIRF only needs to do online registration. } \\
\text { The required documents of some projects are } \\
\text { simplified from complete EIR to simplified EIF, or } \\
\text { from EIF to EIRF. } \\
\text { The review jurisdiction of some projects which have } \\
\text { limited environmental consequences is delegated to } \\
\text { lower levels. }\end{array}$ & $\begin{array}{l}\text { Catalog of Project } \\
\text { EIA }\end{array}$ \\
\hline $\begin{array}{l}\text { Increasing penalties for } \\
\text { violations }\end{array}$ & - The cost of breaking the law is low. & $\begin{array}{l}\text { The fine for proceeding to construction before getting } \\
\text { approval is increased as high as } 1 \%-5 \% \text { of the gross } \\
\text { investment. } \\
\text { Implements the double-penalty system. }\end{array}$ & $\begin{array}{l}2016.7 .2 \\
\text { EIA law (2018) }\end{array}$ \\
\hline $\begin{array}{l}\text { Enhancing interim and } \\
\text { post-event supervision }\end{array}$ & - Pays most attention to the EIA review. & $\begin{array}{l}\text { - Adopts online and offline supervision methods. } \\
\text { - Creates the "intelligence EIA" system. } \\
\text { - Conducts the periodic selective examination of EISs. } \\
\text { - Adopts a lifelong responsibility system and social credi } \\
\text { management system. }\end{array}$ & $\begin{array}{l}2018.1 .25 \\
\text { Advice on } \\
\text { strengthening the } \\
\text { tinterim and } \\
\text { post-event } \\
\text { supervision }\end{array}$ \\
\hline $\begin{array}{l}\text { Increasing public } \\
\text { participation }\end{array}$ & $\begin{array}{l}\text { Three publicity. } \\
\text { - Requires to publicize the brief version of } \\
\text { EIR. } \\
\text { Mainly uses government websites, } \\
\text { newspapers and posters. }\end{array}$ & $\begin{array}{l}\text { The publicity covers the whole EIA process. Six } \\
\text { publicity and above are required. } \\
\text { The contents of each publicity are enriched, and the } \\
\text { whole EIR requires to be exposed. } \\
\text { It also recommends the use of social media platforms } \\
\text { such as WeChat and Weibo. }\end{array}$ & $\begin{array}{l}2019.1 .1 \\
\text { MPPEIA }\end{array}$ \\
\hline
\end{tabular}

Source: regulations and laws; policy interpretations.

Also, the set of reforms were carried out being accompanied by the continuingly promulgation and revision of relevant laws and regulations. For example, the Environmental Protection Law (EPL) was revised in 2014, the EIA Law was revised in 2016 and 2018, the Regulations on Environmental Protection Management of Construction Projects (REPMCP) was revised in 2017, the Measures for Public Participation in EIA (MPPEIA) was issued in 2015 and revised in 2018, and the Technical Guidelines (TGs) have also been revised in recent years. Throughout all those reforms, to improve the effectiveness of EIA is seen as the mainline [6]. However, the question of whether these reforms improve the effectiveness of EIA deserves to be examined. The effectiveness of the reformed EIA system needs to be evaluated. 


\subsection{The Researches on EIA Effectiveness}

As to the effectiveness studies, Environmental Impact Statement (EIS), as the direct outcome of EIA, is an indicator of the performance of the EIA systems and attracts great attention [7]. Besides, comparative case studies are conducted. The EIA system in China is compared with different countries, including the United States, Canada, Japan and Korea [8] [9] [10] [11] [12]. Through checklist comparison, the deficiencies may be found and lessons can be learned from these countries' practices.

Also, some researchers evaluate the performance of specific cases by examining the perception of experts [13] [14]. Wang, Morgan and Cashmore, 2003 [1] evaluated the effectiveness of Project EIA and pointed out that despite the new EIA law (2002), the EIA in China still faces old problems. Ren et al., 2013 [2] analyzed the main reasons for weak EIA enforcement and implementation, which include the political system and incentive mechanisms, institutional arrangements, regulatory and methodological shortcomings. Jia et al., 2011 [15] compared the technical guidelines for Plan EIA between old and new versions. However, the development of EIA in China since 2015 when the "reform storm" started, and the comparison before and after reforms have not been sufficiently discussed by past researches. The most important is that the evaluation model appropriate for the reformed EIA system is not proposed yet.

In 1995, Wood established 14 criteria of an ideal EIA system to test the performance of EIA systems. Ahmad and Wood (2002) [16], additionally added ten criteria and classified them into systemic measures and foundation measures. The systemic measures are defined as "features of EIA systems that are designed to deliver quality assurance in the practice and administration of EIA". They aim at evaluating the performance of EIA system attributes, including legislative provisions, administrative setup and EIA process. Foundation measures are described as "features which promote good practice and underpin the successful application of the systemic approaches", such as training and capacity building. Afterward, Ahmed and Wood's criteria have been extensively used in many countries [17] [18]. Thanks to the including of foundation measures, Ahmed and Wood's ideal evaluation criteria are exactly appropriate to evaluate the reformed EIA system in China, which tend to pay more attention to supervision and penalties.

\subsection{Research Purpose and Method}

Therefore, the present study, first, elaborates on the set of reforms, compare the EIA system before and after reforms. Then, revise Ahmed and Wood's model to make it appropriate for the Chinese context. At last, evaluate the effectiveness of the reformed EIA system against the proposed criteria. Considering that the reforms are mainly about the process of Project EIA, the discussion specifically focuses on Project EIA.

The research framework is shown in Figure 1. We extensively review the leg- 
islations and regulations, official policy interpretations, academic articles and news reports in the past ten years. The formal official documents show well the reform intentions and actions of the government. At the same time, the news reports can speak out the comments of experts, the complaints of public and NGOs, and the suggestions of EIA engineers. As a supplement, we conduct in-depth semi-structured interviews with six senior EIA engineers who have many years of work experience.

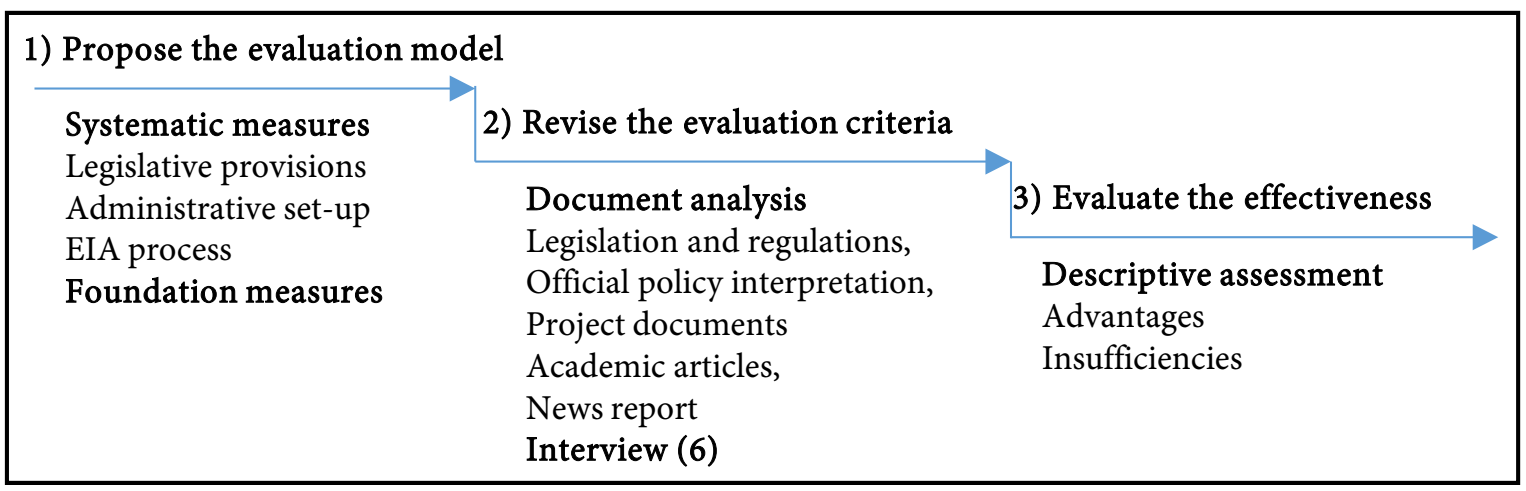

Figure 1. Framework for evaluating the effectiveness of the reformed EIA system.

To revise the evaluation criteria, we identify the important notions mentioned many times in the literature and interviews, then delete the irrelated sub-criteria, add the important ones, and reclassify them. To evaluate the effectiveness of EIA, we conduct the descriptive evaluation, through analyzing the documents and past researchers' comments and supplementing with opinions of interviewees. The interview questions cover all evaluation criteria and the problems we found in the literature review. To guarantee an unbiased survey, we interview with opening questions, for example: "How do you think about...?" In the following discussion, the interviewees are represented by a simple code to preserve their anonymity.

\section{Institutional Arrangements for EIA}

In recent years, the Chinese government carried out a set of reforms on EIA. This section summarizes the main reforms and depicts the reformed EIA system. The description goes along with three crucial components of the EIA system: legislative provisions, administrative setup, and EIA process [19] [20].

\subsection{Legislative Provisions}

The EPL is the backbone of environmental legislation, which is complemented by several specific laws related to environmental elements such as atmospheric, water and noise pollution prevention and control [1]. Besides, a package of laws and regulations describe how EIA should be carried out. Commonly referred to as "one law and two regulations", the most relevant ones are the EIA Law, Regulations on Environmental Protection Management of Construction Projects 
(REPMCP) and Regulations on Planning EIA (RPEIA) [4].

The REPMCP [21] was issued in 1998 and stipulated the environmental protection tool, including "Three Simultaneities (3Ss)" and "EIA". 3Ss requires the environmental protection facilities to be designed, constructed and operated simultaneously with projects, while EIA is responsible for approving the construction of projects. The first version of EIA Law was implemented in 2003 and incorporated into the EIA for Planning. The specific law for Planning EIA, RPEIA, was issued in 2009. As a result, the EIA system of "one law and two regulations" was officially established. With economic growth and social development, reforms were carried out to streamline administration, while strengthening supervision [22]. The EIA Law was revised in 2016 and 2018. And, the law for construction projects, RACPEP, was revised in 2017.

\subsection{Administrative Setup}

Before the reform, environmental protection duties were dispersed in many different departments such as the Ministry of Environmental Protection (MEP), National Development and Reform Commission (NDRC), and Ministry of Agriculture and Rural Affairs (MARA). In 2018, the MEE was established, which integrated the scattered environmental protection responsibilities and took the overall responsibility for environmental management and ecological protection [5]. The Ecological and Environmental Protection Bureaus (EEPBs) at provincial and county levels are responsible for the ecological and environmental protection within their jurisdictions.

The Department of EIA and Emission Management within MEE is in charge of overseeing and coordinating the implementation of EIA and pollutant emission permits nationwide, reviewing the Strategic and Planning EIA, technically re-reviewing the Project EIA and conducting the post-EIA [23]. The Appraisal Centre for Environment and Engineering is responsible for providing technical support, conducting EIA technical reviews and training EIA engineers and EEPB officials [24].

\subsection{EIA Process}

As shown in Figure 2, the process of Project EIA in China is fully compatible with the generic steps that are followed internationally. In the screening phase, projects can be divided into $\mathrm{A}, \mathrm{B}$ and $\mathrm{C}$ three categories using the list and threshold approaches [25]. In the scoping phase, through the preliminary analysis of engineering projects and the baseline analysis of the existing environmental status quo, the environmental impacts can be identified and the evaluation factors can be selected. The environmental factors, which including atmospheric environment, surface water, groundwater, sound, soil environment and ecological impact, all need to be considered. Corresponding to the severity and sensitivity of impacts, working-level from I to III with descending rigorous can be determined (TG). 


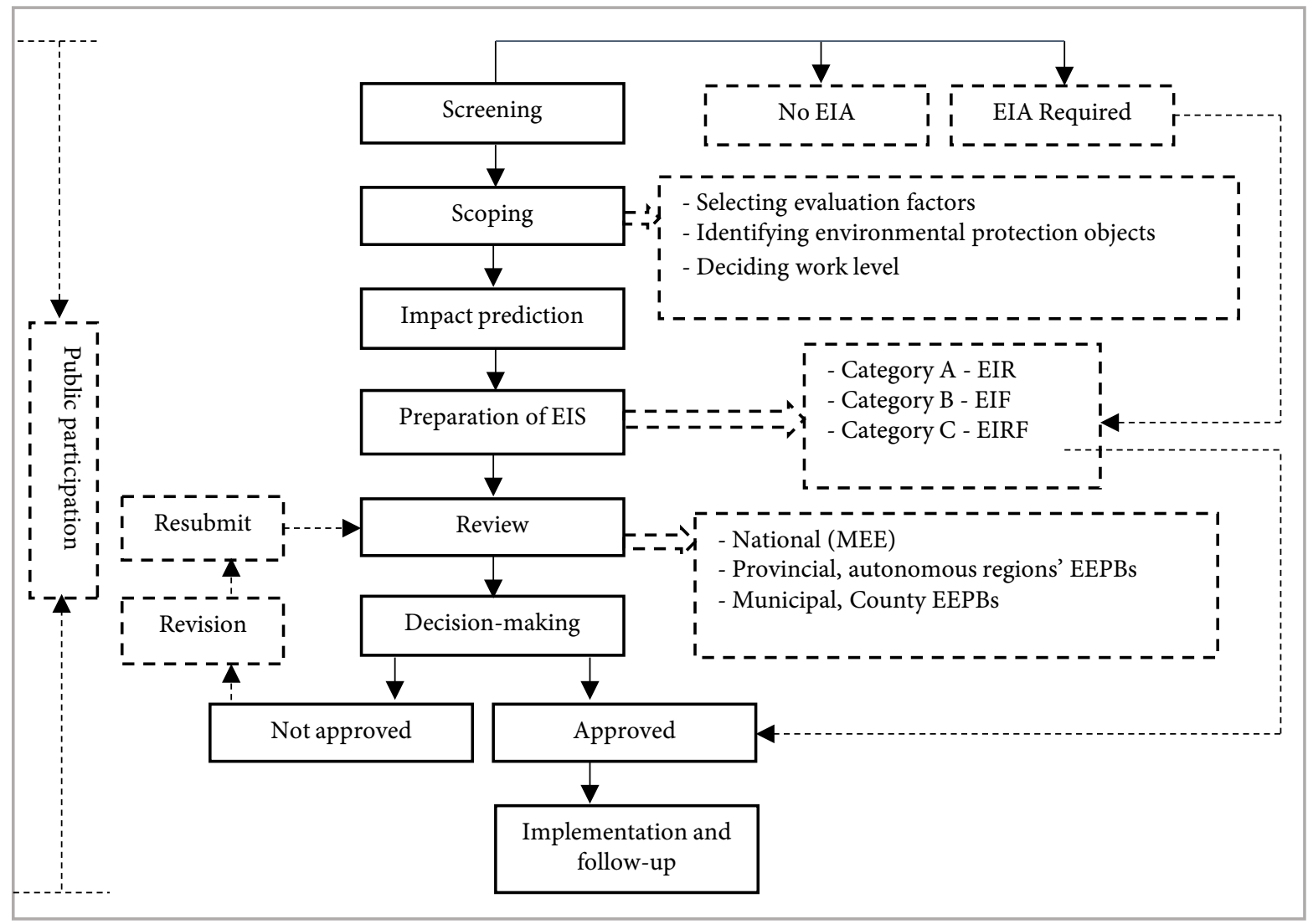

Figure 2. The process of project EIA in China (Source: TGs).

Then, the EISs are compiled from all the above analysis. For low impact C-category projects, developers can compile registration forms (EIRF) by themselves and, thanks to the reform, simply submit them online. For B-category projects, simplified forms (EIF) are sufficient, but detailed reports (EIR) are required for high-impact A-category projects. Before the reform, developers had to contract EIA agencies to compile EIF and EIR. From 2018, developers are also allowed to do it themselves, but the main compilers are required to be qualified engineers. Afterward, the EIR and EIF need to be submitted to the EEPBs to be reviewed and get approval. The final approval of the proposal usually includes a series of conditions under which development may proceed. These conditions need to be followed during the construction, operation and decommissioning of projects.

\section{Evaluation of the Reformed EIA System}

In this section, we evaluate the effectiveness of the reformed EIA system against the revised Ahmed and Wood's criteria. As shown in Table 2, the newly proposed sub-criteria, which are appropriate for the Chinese context, are marked with circles. The sub-criteria which are covered by the reforms are marked with triangles. By effectiveness evaluation, we clarify the advantages of the reforms and point out their inadequacies, which has been shown in Table 3. 
Table 2. The proposed evaluation criteria and revision of Ahmed and Wood's model.

\begin{tabular}{|c|c|c|c|}
\hline Criteria & Sub criteria & $\begin{array}{l}\text { Newly } \\
\text { proposed }\end{array}$ & $\begin{array}{l}\text { Reforms } \\
\text { covered }\end{array}$ \\
\hline \multicolumn{4}{|l|}{ Systemic measures } \\
\hline \multirow[t]{5}{*}{ 1. Legislative Provisions } & s.1 Sufficiency of EIA legal basis & & $\Delta$ \\
\hline & 1.2 Operability of legislation and regulations & • & $\Delta$ \\
\hline & 1.3 Adequacy of technical Guidelines & & $\Delta$ \\
\hline & 1.4 Guidance for EIA implementation at local level & $\bullet$ & $\Delta$ \\
\hline & 1.5 Formal provisions for SEA & & $\Delta$ \\
\hline \multirow[t]{3}{*}{ 2. Administrative set up } & 2.1 Specified EIA review body & & $\Delta$ \\
\hline & 2.2 Existence of supervision authority & • & $\Delta$ \\
\hline & 2.3 Specification of industry authorities' responsibility & & \\
\hline \multirow[t]{9}{*}{ 3. EIA process } & 3.1 Specified screening categories & & $\Delta$ \\
\hline & 3.2 Systematic scoping approach & & \\
\hline & 3.3 Requirement for impacts prediction & & \\
\hline & 3.4 Specified EIS content & & \\
\hline & 3.5 Systematic decision-making approach & & \\
\hline & 3.6 Requirement for monitoring & & \\
\hline & 3.7 Public participation in EIA process & & $\Delta$ \\
\hline & 3.8 Requirement to consider alternatives & & \\
\hline & 3.9 Requirement for EIA follow-up & & \\
\hline \multirow[t]{6}{*}{ Foundation measures } & 4.1 Systematic supervision measures & & $\Delta$ \\
\hline & 4.2 Effective warning and deterrent of penalties & $\bullet$ & $\Delta$ \\
\hline & 4.3 Existence of legislative provisions for appeal & $\bullet$ & \\
\hline & 4.4 Existence of training of various stakeholders & & $\Delta$ \\
\hline & 4.5 Strict quality control system in EIA agencies & ○ & $\Delta$ \\
\hline & 4.6 Coordination with other pollution control measures & $\bullet$ & $\Delta$ \\
\hline
\end{tabular}

The newly proposed sub-criteria, which are appropriate for the Chinese context. $\boldsymbol{\Delta}$ The sub-criteria which are covered by the reforms.

Table 3. The effectiveness evaluation of the reformed EIA system in China.

\begin{tabular}{lll}
\hline Criteria & Performance of Reformed EIA & \\
\cline { 2 - 3 } & Advantages & Inadequacies \\
\hline
\end{tabular}

\section{Systemic measures}

\section{Legislative provisions}

1.1 Sufficiency of EIA legal basis

EPL is supplemented with specific laws on environmental Lacks specific laws for Policy EIA. components and typical industry;

EIA Law is supplemented with specific laws of Projects

EIA and Planning EIA.

1.2 Operability of legislation and regulations
The regulations at national levels are general; The ones at local levels are specific.
The hierarchical position of EPL is not high enough;

Some legal terms are general, easily result in different interpretations. 


\section{Continued}

1.3 Adequacy of technical guidelines

1.4 Guidance for EIA implementation at the local level

1.5 Formal provisions for SEA
- General TG is supplemented with specific guidelines for all environmental components and some industries.

- Exists regulations at the provincial level.

Regulations on Planning EIA was issued in 2009.
- Needs to be revised frequently.

- Lacks supporting laws to guide the implementation of Planning EIA.
Too inflexible, result in unnecessary work

\section{Administrative set up}

2.1 Specified EIA review body

- For EIR and EIF: (1) state environmental protection authority (MEE), (2) provincial, autonomous regions' EPBs, (3) municipal, county EEPBs. For EIRF, online registration is required.

2.2 Existence of supervision authority

- MEE and EEPBs at different levels

2.3 Specification of industry authorities' responsibility

\section{EIA process}

3.1 Specified screening categories List and threshold approach. Projects are classified into three categories: A, B and C, according to their projects' features.

- The pre-review of EIR for some industries was canceled / since 2017.

3.2 Systematic scoping approach

- Identifies the evaluation factors and working levels I-III following TGs, which decides the evaluation scope and ambient standard.

3.3 Requirement for impacts prediction

- Evaluation of environmental status and project engineering analysis; Analyzes each pollution-producing node in production techniques and ecological impacts; Evaluates the monetary value of environmental protection measures cost-benefit analysis.

3.4 Specified EIS content

- Required in article 17 of EIA Law.

Too inflexible

3.5 Systematic decision-making approach

- Adopts technical review meetings.

Although the assessment methodologies are more specific, some regulations are too inflexible. It may lead to unnecessary work.

- Too inflexible Article 11 of REPMCP lists the conditions of not giving EIA approval.

3.6 Requirement for monitoring

- Randomly on-site investigation of projects, periodically selective examination of EISs and real-time monitoring of pollutant emission.

3.7 Public participation in the EIA process

3.8 Requirement to consider alternatives

3.9 Requirement for EIA follow-up

\section{Foundation measures}

4.1 Systematic supervise measures

4.2 Effective warning and deterrent of penalties

4.3 Existence of legislative provisions for appeals
- Public participation almost covers the whole EIA process

- Focuses on technical options.

- Article 27 of EIA Law If the construction and operation of projects are inconsistent with EIA requirements, the EIA follow-up needs to be conducted.

- The interim and post-event supervision has been strengthened.

- The penalties are more severe than before.

- Exists problems at implementation.

- The Law of Executive Accusation is suitable for EIA appeal.
Vertical management reform of environmental monitoring and law enforcement departments under improving.
(1) 


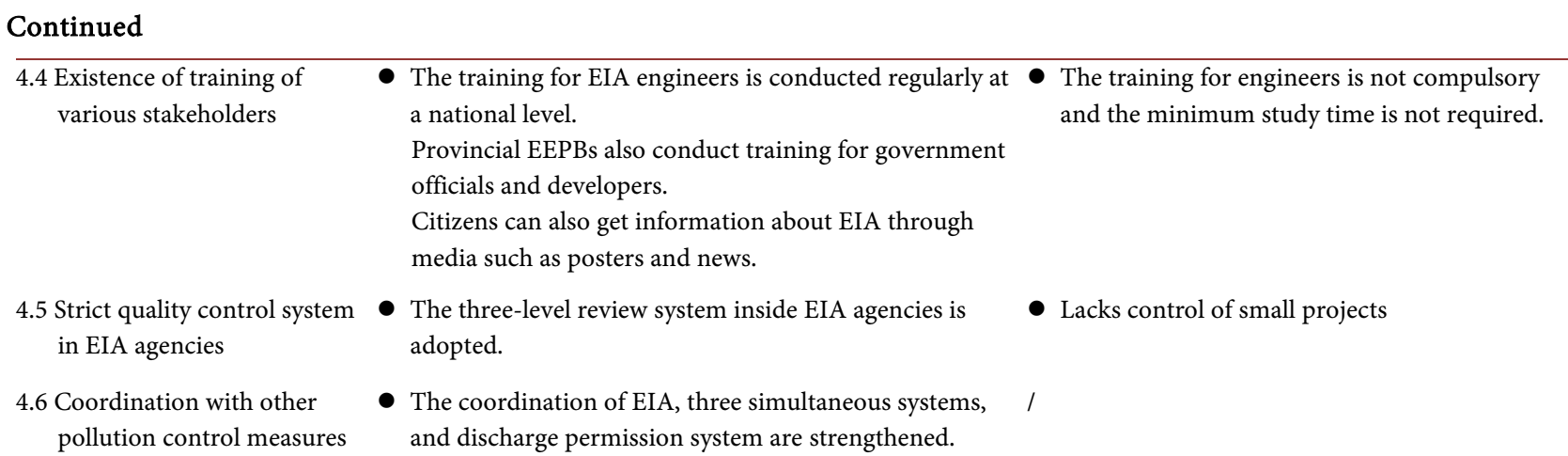

Source: regulations and laws; policy interpretations; past researchers' statement; interviewee's views.

\subsection{Legislative Provisions}

In the past, China paid the most attention to Project EIA, which can only reject the construction of a single project while not influence the initial decision and layout. Nowadays, the Strategic EIA (SEA), which refers to EIA for policies, plans and programs (PPP), has been given more emphasis, aiming to incorporate environmental protection into the decision-making process [26]. Generally, there exists a tiered system among PPP, that starts with the formulation of policy at the upper level, then followed by the plan at the second stage, and the program at the end [27]. However, the SEA hierarchy in China is incomplete.

SEA in China only covers "plan", called Planning (guī huà) EIA (RPEIA). As is required, the Project EIA should be accordant with the local Planning EIA. However, its implementation is low, and many projects still do not have Planning EIA to follow (interviewee \#2, 2019). As to "policy", although the Article 14 of EPL (2015) mentions "the governments need to take the environment into consideration when they formulate economic and technological policies", there are no corresponding regulations to stipulate and guide the implementation of Policy EIA. As to "program", it is missing in Chinese characters [28]. The actions meeting the definition of "program" made by Wood and Dejeddour [27] are, in practice, subject to Project EIA, which makes their EIA measures and technologies inappropriate.

Besides, the revised EPL came into force in 2015 and was regarded as the ever-strictest. However, the hierarchical position of EPL is not high enough to ensure the force of law. EPL has the same hierarchical position as other specific laws, such as Water Law and Forestry Law. That is, the specific laws do not have to be entirely in accordance with EPL [29]. This may lead to a possible conflict between them and give the developers an excuse to comply with specific laws other than EPL. As a result, the strict legal provisions of EPL easily become empty talk.

\subsection{Administrative Setup}

With the implementation of the vertical management reform for EEPBs under the provincial level since 2016, the administrative setup is more efficient and ef- 
fective. The relationship between local governments and environmental protection departments changed. The management of EEPBs altered from local governments to higher-level of environmental protection authorities. The provincial EEPB is in charge of municipal EEPBs, who are supervising counties EEPBs. Besides, the right of law enforcement is decentralized to the municipal and county level. As a result, local governments' responsibility for environmental quality and management has been strengthened [30]. However, this reform is still at the initial stage, and there are still several problems to tackle [31]. For example, how to guarantee the implementation of the environmental responsibility of local governments, how to coordinate the relationship between EEPBs with other local environmental protection departments, and how to strengthen the supervision of local EEPBs. Indeed, this vertical management reform needs to be improved. It is undeniably an excellent attempt to strengthen the overall management of environmental protection in the whole province.

\subsection{EIA Process}

\subsubsection{Screening}

The MEE periodically updates the catalog in response to knowledge, experience and lessons learned over time [2]. With the progress of science and technology, some projects produce fewer environmental impacts than before and can then be moved from Category A to Category B, or from Category B to Category C. For example, the tobacco production factories with an annual output above 300,000 boxes belonged to Category A are now classified into Category B, according to the catalog issued in 2018 [32]. As announced by MEE, in the first half of 2018, the number of projects compiling EIRF represents $80 \%$ of the whole EISs. Among the rest of the projects, only $8 \%$ of them compile the EIRs [33]. Compiling EIRF is more time and cost-efficient than EIR. In short, with the decentralization and adjusting of the projects list, the workload for the central and provincial governments decreased significantly.

\subsubsection{Scoping}

With the social development and economic growth, pollution control technology, pollutant discharge standards, and environmental assessment technology have significantly changed. Thus, the Technical Guidelines (TGs) of general program, atmospheric environment, surface water, groundwater and soil, have been revised in recent years. The exposure drafts of TGs of sound and ecological impact have also been issued in 2019 [34] [35]. The new TGs adjusted the method of identifying working levels, amended the assessment content of each working level and updated the technology of assessment. Overall, the scientific rigor of the assessment increases. Interviewee \#1 said: "the environmental standards are much stricter than before." However, some terms are still ambiguous, and the different experts may have different interpretations, which makes the engineers confusing (interviewee \#3). Some TG regulations are too inflexible. The small projects are also required to cover some unnecessary contents, which 
may lead to needless work (Interviewee \#4).

\subsubsection{Preparation and Review of EIS}

With the implementation of the decentralization policy, the review efficiency has been dramatically improved. In the 2018 fiscal year, the number of construction projects conducting EIA is 91,686 in total, among which only 22 projects got approval from MEE at the national level. Besides, around $80 \%$ of construction projects do not need to be reviewed and only required to do online registration because of the canceling of review of EIRF [33] [36].

However, local governments, driven by the desire of economic development, tend to give EIA approvals to polluting industries leniently. In March and April of 2015, two low thermal coal power generation projects were rejected by the national MEP for several reasons, including insufficient pollutant treatment technology and utilities and the excessive regional overcapacity of pollutant discharge. With the delegation of review responsibility of the thermal power industry from the national level to the provincial level since May 2015, these projects got the EIA approval from EEPB of Shanxi Province. Later in the same year, Shanxi province also gave EIA approvals to 21 similar projects within three months. The total installed capacity of those projects is significantly excessive [37]. Therefore, the balance between regulation and centralization is hard to achieve. The catalogs need to be continually adjusted.

\subsubsection{Monitoring}

The follow-up monitoring measures are diverse and comprehensive, which is essential to ensure the concrete implementation of EIA. They cover both the construction and operation phases of projects. The developers are required to submit the results of monitoring during the construction phase to obtain operational approval from EPBs [1]. The environmental protection acceptance (EPA) is adopted to supplement the EIA. The EPA report is to examine and record the big changes of projects' nature, scale, location, production techniques, pollution control measures, or ecology protection methods, the monitoring of the environmental impacts during the construction phase, and the implementation situation of 3Ss systems [38].

In 2017, the administrative examination and approval of EPA by EPB was canceled, and the developers are required to complete the online EPA by themselves and take the whole responsibility for the result (REPMCP). The developers can compile the EPA reports by themselves or contract the agencies to help them, then invite the relevant experts and government officials to give comments. As a result, the responsibility changed to the developers. The excellent point is that it encourages developers to pay more attention to environmental protection on their initiatives, not being compelled by the government. The problem lies in the insufficient capacity of developers. Interviewee \#1 and \#5 said that "The developers always feel confused about the EPA process, they still invite experts and government officials to give comments." 


\subsubsection{Public Participation}

Public participation is obligatory in the EIA process. The revised MPPEIA (2018) declares a broader scope of the public which includes the citizens, legal representatives and other organizations being influenced within the EIA scope. The ways of information disclosure are various that are defined as network, newspapers and posting announcements. The content of disclosure is more detailed. Besides, the penalties are more severe, if any deception is found in the collection of public opinions, the information on construction projects, their legal representatives, and the EIA engineers may be disclosed to the public. Overall, the new MPPEIA makes public participation much more implementable. With the increasing awareness of environmental and civil rights, public participation is improving (interviewee \#4 and \#5).

\subsubsection{Consideration of Alternatives}

Consideration of alternatives lies at the heart of EIA while it is inadequately carried out in many countries [39]. Although the General TG (2011) requires all EIAs to consider project alternatives (Article 14, TG), the alternatives being considered only remain technical options such as variation of the project site, alignment, size, production process, environmental impacts and carrying capacity of the local environment. However, the strategic alternatives such as "without project" or "delay the project", are not mentioned [2] [40]. Interviewee \#4, \#5, and \#6 agreed that before conducting the Project EIA, there is an acquiescent condition that this project will finally be constructed; the only thing EIA needs to do is setting the requirements it should comply.

\subsection{Evaluation of Foundation Measures}

\subsubsection{Supervision}

In 2018, MEE promulgated the Implementation Opinions on Strengthening the Interim and Post-Event Supervision of Construction Project EIA. The Opinions claims that with social development and economic growth, it is time to relax the pre-construction approval while strengthening the interim and post-event supervision. It requires that the interim supervision includes the legality and validity of the EIA review, the professionality of technical review organizations, the facticity of EISs, the compliance of developers, and the involvement of public participants. The post-event supervision includes the monitoring of three simultaneous (3Ss) by EEPBs, the selective examination and recheck of EISs and the implementation of EIR by developers [41]. At the same time of simplifying EIA approval, the coordination of EIA, 3Ss system, and discharge permission system are strengthened (interview \#1, \#4 and \#5).

Online and offline supervision methods are adopted. The "Intelligence EIA" system integrates the online EIA review system with other environmental management systems such as EPA system and EIRF record system. While realizing online management, EIA data are collected. Using the provided data, the supervision departments can conduct supervision through on-site inspection, remote sensing check, and satellite verification. In 2018, the MEE began to conduct se- 
lective examination every three months. The results of the examinations are publicized on the government website.

To further ensure the quality of EISs, the lifelong responsibility system and credit management system were also adopted. The EIA engineers compiling one EIS need to be responsible for the quality of this EIS in their whole life. Whenever some severe quality problems of EIS have been found, the related engineers are held accountable (EPL, RPEIA, IDMRAE (trial)). Besides, the relevant information of developers, projects and EIA agencies and engineers is required to publicize to the public on the online credit management system. For EIA agencies and engineers, their credit files are required to be established, and the penalties mentioned in EIA Law are reflected in their credit score. Because of all these supervision methods, the engineers feel enormous pressure and try to ensure the quality of EISs (interviewee \# 1, and \#2).

\subsubsection{Penalties}

The fourth chapters of the EIA Law and REPMCP titled "Legal Liability" describe the penalties for violations to environmental authorities, agencies, developers and related personnel. For developers, who were found conducting illegal construction and operation, can remedially apply for the EIA approval after paying fines. However, the fines were much lower than the profits of developers' illegal operations. Thus, many developers prefer to pay fines rather than obey the legal process. In 2015, the EIA Law was revised, and this remedial measure was abolished. The fines have been increased as high as $1 \%-5 \%$ of the gross investment (Article 31, EIA Law 2016). It means that for the projects whose investment is above a hundred million, the fine can be significantly high. For those projects who illegally discharge pollutants and fail to rectify it within 30 days, the daily accumulated fines may be charged from the day they are required to rectify (Article 59, EPL 2014).

As to EIA agencies, the double-penalty system is adopted, which means that, if the EISs are found having severe quality problems, both related organizations and personnel are punished (Article 31 and 32, EIA Law 2016). If any corruption is found during the EIA review process, the responsible environmental authorities may be given administrative or criminal penalties (Article 34, EIA Law 2016). Indeed, after these reforms, penalties became more severe, and the legal force much more robust.

\subsubsection{Appeal}

Under the Administrative Litigation Law, the administrative decisions made by EPBs at all steps of the process of Project EIA, such as administrative penalties, examination, information disclosure, neglect of statutory duty and compensation, can all be challenged in courts (ALL, 2017). However, Planning is not subject to judicial review. From 2000 to 2014, even though the overall number remained low, the number of lawsuits grew gradually [42]. However, EPBs were overwhelmingly successful in the challenges under EIA law. In almost $80 \%$ of 
cases, EPBs defendants were cleared of charges. Among them, some court decisions did the judges of sustaining EPB's EIA decisions, while in most cases, the judges simply rejected the lawsuits or overruled the plaintiff s claims. It can be found that the judges tend to be highly self-restrained and deferential in reviewing EPBs' EIA decision [42]. Thus, it is essential to avoid the complicated trade-offs and balances under the judicial review, and further protect the right of action of developers, residents, and environmental groups.

\subsubsection{Capacity Building}

The capacity of government officials in China remains limited. To give the final approval to developers, EEPBs usually consult with EIA experts in the review meetings. Particularly, with the delegation of review authority to the county level, the local EEPB officials even do not know how to conduct the EIA review process (interviewee \#1, \#2 and \#6). For the last several years, more provincial EEPBs begin to organize EIA experts to give policy interpretations for government officials and developers, which is helpful to improve their understanding of the EIA policy and review process.

As to EISs engineers, the Environmental Engineering Assessment Centre of MEE regularly conducts training courses about different professional skills. The unregistered and registered EIA engineers can selectively attend. Except for the training courses, they can also take the online study course (GCBCPEIA (trial), 2019). However, the attendance of training is not compulsory, and the minimum study time is not required. Interview \#3 said that "some engineers escape from the courses for saving training expenses." It is difficult to guarantee their competency and capacity.

\section{Conclusions}

This study creatively proposes an evaluation framework appropriate for the Chinese context by revising Ahmed and Wood's (2002) model. Also, we elaborate on the reforms on EIA carried out since 2015 and evaluate the effectiveness of the reformed EIA system. Four main criteria are covered, among which legislative provisions, administrative setup and EIA process are concerning to systematic measures, the methods aiming at promoting successful application belong to foundation measures.

With the implementation of reforms, a set of corresponding laws and regulations were issued or amended. The revised EIA Law and TGs are more stringent than the old versions. The revised EPL was regarded as the ever-strictest. However, EPL has the same hierarchical position as other specific laws, which makes the strict legal provisions of EPL easily become empty talk. Although SEA has been paid increasing attention, there still lack specific laws for Policy EIA and supporting laws to guide the implementation of planning EIA.

As to the administrative setup, government management is more efficient and effective. The establishment of the MEE in 2018 opened a new era of "su- 
per-ministry". It takes the overall responsibility for environmental management and ecological protection. Besides, the vertical management reform on environmental monitoring and enforcement departments was widely conducted below the provincial level. It is expected to realize the overall management of environmental protection at the national and provincial levels. However, what the overall management explicitly entails and how to realize it remain unclear. The coordination of different local government departments is also challenging.

To respond to the reforming principle of "streamline administration, delegate more powers, improve regulation and provide better service", the EIA process is greatly simplified. For example, the pre-reviews of EIS by industrial authorities are canceled, the review of the EIA registration form is simplified as online registration, and some projects previously reviewed by higher authority are delegated to lower levels. The EIA approval is efficient than before.

While relaxing the pre-construction approval, the interim and post-event supervision activities are strengthened and penalties are more severe. The coordination between EIA and pollutants discharge permit systems is promoted. The "Intelligence EIA" system is adopted to conduct online supervision. The offline examinations of EISs are conducted regularly. The credit management system and lifelong responsibility system are adopted to constrain the EIA agencies and engineers. Besides, training courses are launched to improve the capacity of officials and engineers. All these measures make the engineers feel pressure to ensure the quality of EISs.

Overall, despite the problems occurring at the initial phase of the reforms, the effectiveness of the reformed EIA system is significantly improved. China simplifies the approval of Project EIA while strengthening the post-event supervision and its coordination of pollutants discharge permit system. In the foreseeable future, the role of Project EIA will be weakened, while the implementation of SEA will be improved.

In this study, we clarify the advantages of reforms, point out their inadequacies, and further put forward several recommendations. Our study is mainly based on document analysis and literature review, which is supplemented with in-depth interviews. It may helpfully provide comprehensive information and understanding of the EIA system for future EIA effectiveness evaluation research in the country, such as discussion of its substantive, transactive, normative effectiveness.

\section{Acknowledgements}

This work was supported by the Chinese Government Scholarship. (CSC No. 201808050176.) Great thanks are given to Professor Makoto Usami and Dr. Laÿna Droz-dit-Busset for their precious comments and correction of grammar.

\section{Conflicts of Interest}

The author declares no conflicts of interest. 


\section{References}

[1] Wang, Y., Morgan, R.K. and Cashmore, M. (2003) Environmental Impact Assessment of Projects in the People's Republic of China: New Law, Old Problems. Environmental Impact Assessment Review, 23, 543-579. https://doi.org/10.1016/S0195-9255(03)00071-4

[2] Ren, X. (2013) Implementation of Environmental Impact Assessment in China. Journal of Environmental Assessment Policy \& Management, 15, 1350009. https://doi.org/10.1142/S1464333213500099

[3] People.cn (2015) The Feedback of Special Inspection to the Ministry of Environmental Protection from the Central Government's Third Inspection Team. http://politics.people.com.cn/n/2015/0210/c1001-26542556.html

[4] Bao, C. (2015) Reform of Environmental Impact Assessment Aims to Return to Its Essence. Chinese Environmental Management, 7, 33-39.

[5] Ma, T. and Liu, Q. (2018) China Reshapes Ministries to Protect Environment Better. China Dialogue. https://dialogochino.net/10837/

[6] Bao, C. (2016) EIA Reforms Should Focus on Improving Effectiveness. Chinese Ecological Civilization, No. 5, 33-35.

[7] Jin, G. (2017) Researches on the Effectiveness of Construction Projects EIA in Jilin Province. Journal of Changchun Institute of Technology, 18, 86-92.

[8] Ren, Y. (2017) Comparative Analysis of the Environmental Impact Assessment System between China and the United States. Energy and Energy Conservation, No. 1, 98-99.

[9] Qiao, H. (2007) A Comparison between EIA Systems of China and the UK. Shanghai Environmental Sciences, No. 3, 117-120.

[10] Li, Y. (2017) A Comparative Study on Chinese and Canadian Legal System of Environmental Impact Assessment. Master's Dissertation, China University of Geosciences, Wuhan.

[11] Zhang, X. (2010) The Comparison Research of EIA System in China and Japan. Master's Dissertation, Jiangxi University of Science and Technology, Ganzhou.

[12] Wu, L. (2016) A Comparative Study between the EIA System of China and Korea. Master's Dissertation, Hunan Normal University, Changsha.

[13] Wang, H.Z., Bai, H.T., Liu, J. and Xu, H. (2012) Measurement Indicators and an Evaluation Approach for Assessing Strategic Environmental Assessment Effectiveness. Ecological Indicators, 23, 413-420. https://doi.org/10.1016/j.ecolind.2012.04.021

[14] Zhou, K.-Y. and Sheate, W.R. (2011) Case Studies: Application of SEA in Provincial Level Expressway Infrastructure Network Planning in China-Current Existing Problems. Environmental Impact Assessment Review, 31, 521-537. https://doi.org/10.1016/j.eiar.2010.10.005

[15] Jia, H., et al. (2011) Experts' Perspective on the Performance of Chinese Technical Guidelines for Plan Environmental Impact Assessment. Environmental Impact Assessment Review, 31, 587-592. https://doi.org/10.1016/j.eiar.2011.01.005

[16] Ahmad, B. and Wood, C. (2002) A Comparative Evaluation of the EIA Systems in Egypt, Turkey and Tunisia. Environmental Impact Assessment Review, 22, 213-234. https://doi.org/10.1016/S0195-9255(02)00004-5

[17] Naser, H.A. (2012) Evaluation of the Environmental Impact Assessment System in Bahrain. Journal of Environmental Protection, 3, 234-239. 
https://doi.org/10.4236/jep.2012.32029

[18] Khosravi, F., Jha-Thakur, U. and Fischer, T.B. (2019) Evaluation of the Environmental Impact Assessment System in Iran. Environmental Impact Assessment Review, 74, 63-72. https://doi.org/10.1016/j.eiar.2018.10.005

[19] Wayakone, S. and Makoto, I. (2012) Evaluation of the Environmental Impacts Assessment (EIA) System in Lao PDR. Journal of Environmental Protection, 3, 1655-1670. https://doi.org/10.4236/jep.2012.312182

[20] Marara, M., et al. (2011) The Importance of Context in Delivering Effective EIA: Case Studies from East Africa. Environmental Impact Assessment Review, 31, 286-296. https://doi.org/10.1016/j.eiar.2010.10.002

[21] Ning, D., Wang, H. and Whitney, J. (1988) Environmental Impact Assessment in China: Present Practice and Future Developments. Environmental Impact Assessment Review, 8, 85-95. https://doi.org/10.1016/0195-9255(88)90062-5

[22] Liu, Y. (2019) Analysis on the Approval and Supervision of Environmental Impact Assessment under the Background of "Disposal of Clothing"-A Case Study of Gui'an New District. Environment and Development, No. 1, 200-201.

[23] MEE (2018) Environmental Impact Assessment and Emission Management Division.

http://www.mee.gov.cn/xxgk2018/xxgk/zjjg/jgsz/201810/t20181008_644811.html

[24] MEE (2020) Environmental Engineering Assessment Center of the Ministry of Ecology and Environment. http://www.china-eia.com/zxjj/

[25] Suwanteep, K., Murayama, T. and Nishikizawa, S. (2016) Environmental Impact Assessment System in Thailand and Its Comparison with Those in China and Japan. Environmental Impact Assessment Review, 58, 12-24. https://doi.org/10.1016/j.eiar.2016.02.001

[26] Wang, S.J., et al. (2009) The Development and Practices of Strategic Environmental Assessment in Shandong Province, China. Environmental Impact Assessment Review, 29, 408-420. https://doi.org/10.1016/j.eiar.2009.02.005

[27] Wood, C. and Dejeddour, M. (1992) Strategic Environmental Assessment: EA of Policies, Plans and Programmes. Impact Assessment, 10, 3-22.

https://doi.org/10.1080/07349165.1992.9725728

[28] Zhou, K.Y. and Sheate, W.R. (2011) EIA Application in China's Expressway Infrastructure: Clarifying the Decision-Making Hierarchy. Journal of Environmental Management, 92, 1471-1483. https://doi.org/10.1016/j.jenvman.2010.12.011

[29] Chang, J. (2014) New Act on Environmental Protection: The Strictest Environmental Law and the Hardest Law on Enforcement in Chinese Legislative History. Environmental Protection, No. 10, 23-28.

[30] MEE (2016) Pilot Work of the Vertical Management Reform of Environmental Monitoring and Enforcement Departments below the Provincial Level.

[31] Tan, X. (2018) Discussion of the Vertical Management Reform of Environmental Monitoring and Enforcement Departments below the Provincial Level. http://views.ce.cn/view/ent/201808/22/t20180822_30098316.shtml

[32] MEE (2018) Some Revisions on the "Catalogue of Construction Projects EIA". http://www.mee.gov.cn/gkml/sthjbgw/sthjbl/201804/t20180430_435750.htm

[33] MEE (2018) Further Improve the Efficiency of EIA Review. http://www.gov.cn/xinwen/2018-09/02/content_5318701.htm

[34] MEE (2020) List of “Technical Guidelines for Environmental Impact Assessment”. http://www.mee.gov.cn/ywgz/fgbz/bz/bzwb/other/pjjsdz/ 
[35] Pediaditi, K., et al. (2018) Greece's Reformed EIA System : Evaluating Its Implementation and Potential. Environmental Impact Assessment Review, 73, 90-103. https://doi.org/10.1016/j.eiar.2018.07.007

[36] MEE (2017) Ministry of Environmental Protection's Notification of the Results of Investigation on National EIA Agencies. https://www.nengapp.com/news/detail/906942

[37] NGO (2015) With the Delegation of Review Responsibility, the Total Installed Capacity of Thermal Power Projects Is Significantly Excessive. Center, Chongqing Liangjiang Volunteer Service Development.

https://site.douban.com/134644/widget/notes/7538582/note/517201734/

[38] MEP (2017) Interim Measures for Environmental Protection Acceptance of Completed Construction Project.

[39] Gałaś, S., et al. (2015) Environmental Impact Assessment in the Visegrad Group countries. Environmental Impact Assessment Review, 55, 11-20. https://doi.org/10.1016/j.eiar.2015.06.006

[40] Ruan, L. (2016) Discussion of the Legal Effect of Review Conclusion of Environmental Impact Assessment. Journal of Jishou University, 37, 25-29.

[41] MEP (2018) Replies for the inquiries of "Implementation Opinions on Strengthening the Interim and Post-Event Supervision of Construction EIA" from the Ministry of Environmental Protection.

http://www.mee.gov.cn/gkml/hbb/bwj/201801/t20180131_430627.htm

[42] Jin, Z.N. (2015) Environmental Impact Assessment Law in China’s Courts: A Study of 107 Judicial Decisions. Environmental Impact Assessment Review, 55, 35-44. https://doi.org/10.1016/j.eiar.2015.06.008 
Supplementary Material

Appendix A. List of Abbreviations

\begin{tabular}{ll}
\hline EIRF & Environmental Impact Registration Form \\
MEE & Ministry of Ecology and Environment of the People's Republic of China \\
MEP & Ministry of Environmental Protection \\
EIS & Environmental Impact Statement \\
3Ss & Three Simultaneities \\
EPL & Environmental Protection Law \\
EIA Law & Environmental Impact Assessment Law \\
REPMCP & Regulations on Environmental Protection Management of Construction Projects \\
RPEIA & Regulations on Planning Environmental Impact Assessment \\
TG & Technical Guideline \\
NDRC & National Development and Reform Commission \\
MWR & Ministry of Water Resources \\
MARA & Ministry of Agriculture and Rural Affairs \\
EEPB & Ecological and Environmental Protection Bureaus \\
EIS & Environmental Impact Statement \\
EPA & Environmental Protection Acceptance \\
PDP & Pollutant Discharge Permit \\
\hline
\end{tabular}

\section{Appendix B. Reference of Important Laws and Regulations}

1) Environmental Impact Assessment Law (Presidential Decree of the People's Republic of China [2016] No.48)

2) Regulations on Environmental Protection Management of Construction Projects (Decree of the State Council of the People's Republic of China [2017] No. 682)

3) Administrative Litigation Law (Presidential Decree of the People's Republic of China [2017] No.16)

4) Environmental Protection Law (Presidential Decree of the People's Republic of China [2014] No.9)

5) Regulations on Planning Environmental Impact Assessment (Decree of the State Council of the People's Republic of China [2009] No.559)

6) Guidance on Capacity Building for Construction Projects Environmental Impact Assessment Report (Form) (Trial) (Decree of the Ministry of Ecology and Environment [2019] No.9)

7) Measures for Public Participation in Environmental Impact Assessment (Ministry of Ecology and Environment of People's Republic of China [2018] No.4) 